\begin{tabular}{|c|c|c|}
\hline \multirow{2}{*}{ IDUNAS } & NATURAL \& APPLIED SCIENCES & 2021 \\
& Vol. 4 \\
No. 2 \\
$(1-15)$
\end{tabular}

\title{
Machine Vision Supported Quality Control Applications in Rotary Switch Production by Using Both Process FMEA and Design FMEA
}

\author{
Research Article

\begin{abstract}
İsmet $\operatorname{Karacan}^{1 *(D)}$, İnanç Erdoğan ${ }^{* * i D}$, M. Cem İğdil ${ }^{1 *(i D}$, Ufuk Cebeci²*iD
${ }^{1}$ AN-EL Anahtar ve Elektrikli Ev Aletleri A.Ş., Velibaba Mah., Ankara Cad., No:188, Pendik, 34896, İstanbul/Türkiye.

${ }^{2}$ Industrial Engineering Department, İstanbul Technical University, İstanbul, Türkiye.
\end{abstract} \\ Author E-mails \\ anelprs142@an-el.com.tr \\ anel@an-el.com.tr \\ arge6@an-el.com.tr \\ cebeciu@itu.edu.tr \\ *Correspondance to: İsmet Karacan, AN-EL Anahtar ve Elektrikli Ev Aletleri A.Ş., Velibaba Mah., Ankara Cad., \\ No:188, Pendik, 34896, İstanbul/Türkiye. \\ DOI: 10.38061/idunas.850545
}

Received: 30.12.2020; Accepted: 04.03.2021

\section{Abstract}

Emerging in the past few decades, Industry 4.0 has wide effects over production lines with an increasing number of novel applications. These applications implement more than one of the tools of Industry 4.0. These tools include but are not limited to internet of things (IoT), big data, cloud computing, artificial intelligence, augmented reality, virtual reality, machine to machine communication (M2M), smart robot applications, etc. The aim of these efforts is mainly to acquire smarter manufacturing systems. With spreading Industry 4.0 methodologies, the role of sensors became more important to respond to new demands. One of the most important sensor types in this sense is the camera which now has wide variants in different forms. Applying machine vision algorithms via cameras grants optimization of many critical processes. In this perspective, the quality of both product and process should be handled as a key performance indicator that may be continuously enhanced for excellence. Machine vision algorithms may be adapted to check and manage quality in designated control points on the production lines. This study focuses on the control of the quality of rotary switches that are widely used in household appliances like ovens and washing machines. Rotary switches are critical components of an appliance since they direct the flow of electricity within the product. A failure in the functionality of this component directly causes the failure of the main product. Hence, the quality rate of rotary switches should be calculated in defective parts per million (dppm) units. An intense quality control procedure is required to achieve low dppm rates during production. As a real-life application, a camera system is integrated into the rotary switch production line on a selected point. Classification algorithms are developed on a cost-effective platform to perform visual quality checks of the rotary switches and qualify as "Ok" or "Defective". The selected point ensures a high percent check of quality criteria while enabling repair of the defective parts with minor interventions. This control aims to identify a defective rotary switch as soon as possible since most of the defects are irreversible 
once the rotary switch is totally produced or even some processes are completed. In this case, the entire product should be set apart for scrap.

Another originality of our study is applying both Process Failure Mode and Effect Analysis (PFMEA) and Design Failure Mode and Effect Analysis (DFMEA) together. There is almost no referenced study in the literature.

Benchmark comparisons are conducted upon completing the integration of the new system to the production line. As a result, enhancements in the quality, cost, and production speed parameters are achieved with a cost-effective smart system. Additional capabilities are added to the system, namely data analyzing online data feeding.

Keywords: Machine vision, Industry 4.0, Quality Control, FMEA, Poka-Yoke

\section{INTRODUCTION}

With rapidly developing technologies, consumer behavior has been exposed to changes concerning purchasing habits. The simplicity of the e-Commerce experience has especially increased the number of criteria that are considered during the selection of a product or a service [1]. With this change, manufacturers also updated their strategies to manage customer demand to enable them to compete in the market. For instance, agile manufacturing is a newly emerging methodology that is based on adding value to the customer with short-term and high-frequency sprints [2]. One of the key criteria considered is the customer's perception of the brand on quality. Many firms spend their years increasing their loyalty by releasing high-quality end products. One of the aspects of this success is improving the quality control capabilities during the production process. Many soft and hard tools have been developed to ensure that products are manufactured within defined quality limits. Statistical Process Control, histograms, Poka-Yoke devices are widely used examples of control tools.

Global technological developments force producers to perpetually enhance their key operational skills. Industrial revolutions have been providing key guidance for these technology-driven steps. The up-to-date concept of Industry 4.0 is mainly based on data and knowledge-related tools. Recent advances in sensors and computational power encourage developers to implement novel applications developed with complex algorithms. Machine vision-supported classification algorithms are widely used to have more robust quality inspections to avoid defective parts during the process.

A rotary switch is an electrical component with multiple positions that provides the requested terminal sequence in accordance with the corresponding function diagram. Rotary switches are widely used for the manufacturing of household appliances like ovens and washing machines. Accoupled with a control knob, rotary switches shift the electrical functioning state of the appliance once the knob is rotated by the user. Hence, rotary switches are critical elements that directly affect the performance of the appliance. As a result, intensive care should be spent during the production phase of switches to avoid any functional defect.

In this study, we describe a low-cost machine vision Poka-Yoke (Mistake Proofing) application that is empowered by a Decision Tree Classifier algorithm to detect defective parts during the rotary switch production process. The hardware consists of a Raspberry Pi-based computing system, touch panel for operators, camera, lighting, and custom interface PCB for the connection to the production system. OpenCV library is deployed to handle machine vision operations and classification algorithms are coded in Python language. The distinguishing approach of this study is the utilization of FMEA methods. This application is assessed by both PFMEA and DFMEA during the development phase. To the best of the authors' knowledge, this is the first study that integrates PFMEA and DFMEA in a visual quality control application. Section 2 includes a literature review of similar applications. Section 3 describes the proposed methodology. The results are shared in Section 4. Final remarks and conclusions are included in Section 5. 


\section{LITERATURE REVIEW}

\section{Machine Vision Supported Quality Control}

For the sake of rapidly improving technology, Commercial off-the-shelf (COTS) products are widely preferred to include in cost-effective optimization solutions. One of these fields is the optical process and quality control during production. This study suggests a Raspberry Pi-based application for quality control on a production line. Similar approaches exist in the literature for production lines. Louw and Droomer [3] proposed a Raspberry Pi-based hardware system to defects on toy trains in which OpenCV has been implemented for machine vision operations and Python has been selected for coding statistical classifiers. Würschinger et al. [4] applied Convolutional Neural Networks (CNN) algorithm on Raspberry Pi to suggest an enhanced and low-cost deep learning solution for manufacturing lines where they try to detect chips on piston rods via a deep learning algorithm with two classes. In another application by Ardhy and Hariadi [5], Raspberry Pi, Python, and OpenCV integration has been utilized to inspect Printed Circuit Board (PCB) defects and authors suggested Adaptive Gaussian Threshold as the best defect identifier. The study for welding visual inspection by Gong et al. [6] also suggests a low-cost system where they inspect the quality of welding on circuits via a Support Vector Machine Algorithm. Korodi et al. [7] deploy another low-cost visual system to control quality Electronic Control Unit (ECU) control in the automotive industry. The proposed system checks the missing or defective pins, clips, cracks on electronic boards, etc. with the help of a visual control system. Merging the data by a parallel acquisition and parallel processing the information methodology, they provide a robust defect detection system where the produced components are safety-critical. Adamo et al. [8] joined several CMOS cameras to acquire the image of satin glass in production lines. The acquired image was processed via the Canny edge detection algorithm. Frustaci et al. [9] suggested another embedded machine vision system for geometric inspection for planar or rotational shifts on the product in the context of Industry 4.0. The target product for quality control is the catalytic converter on which they applied image processing steps as image acquisition, conversion from RGB to grayscale, Region of interest (ROI) filtering for removing noise, Canny edge detection algorithm, Contour selection, Morphological filtering, and Center detection. Without having integrated to production lines, Parakontan and Sawangsri [10] designed another Raspberry-Pi-based system to control the quality of printed circuit boards (PCB) against copper leakages by transforming RGB images to binary images. Leo et al. [11] developed a two-camera vision system to detect multiple types of defects about dimensions and shapes on electromechanics part production and integrated the system into the production line. The proposed architecture of the study includes the integration of two cameras to a Programmable logic controller (PLC) via an industrial PC where data acquisition algorithms run. The system was managed by Labview software. Moru and Borro [12] developed a custom application on Machine Vision to control dimensions of produced gears on production lines. To avoid measuring errors as much as possible and provide enhanced tolerances, their proposed system includes the acquisition of the image with telecentric lenses and intense calibration operations. Another contribution of their study is the methodological approach for determining uncertainty associated with their proposed measurement process.

Revealing the literature shows that many studies have been proposed with different configurations according to the application area, size of the project, demand for computational power, the budget of the project, integrability to the production line, etc. Many requirements could be met by Raspberry Pi-based low-cost systems, where a moderate hardware performance with an open-source image processing/classification algorithm may provide the necessary performance. For more demanding computations like deep learning or integration requirements, a common combination is the integration of industrial cameras to PLCs via industrial PCs. Independent from the hardware, OpenCV is the most widespread image processing software that is applied for image acquisition and processing purposes like binarization, converting, filtering, etc. in these projects. The current trend of studies advises that machine 
vision applications will drastically increase to be integrated into automated systems where intense quality control activities are required.

\section{Decision Tree Classifier (DTC)}

Classification methodology is the systematic process of categorizing entities according to the defined criteria. A Decision Tree Classifier stays among many alternatives of multistage classifiers [13]. The process is used to predict a target variable [14]. The target variable may be continuous or categorical. The method has many applications in production systems. Wang et al. suggested a new approach that can identify patterns of control charts [15]. Matsko et al. proposed an adaptive fuzzy classifier that has a dynamic structure that can be adapted to control Automatic Process Control Systems [16]. Putri et al. prepared a decision tree that reflects the methodology of identifying defects on a grinding wheel [17].

Integration of Visual Quality Control and Decision Tree Classifiers are also common in production. Cheng et al. implemented an online machine vision-supported decision tree algorithm to ease the decisionmaking process of combine harvesters on impurities of rice grain [18]. Zhou et al. suggested another machine vision system that can detect surface defects of automobiles during their production [19]. Lin et al. developed a machine vision-supported decision tree classifier that can reveal defects of optic lenses in their manufacturing phase [20]. There are many different examples in the literature for various types of productions since the methodology can manage to identify many types of "defects". In this study, the Classification and Regression Trees (CART) classification algorithm which was proposed by Breiman et al. [21] preferred since the algorithm is appropriate to manage binary or categorical parameters and variables.

\section{Failure Mode and Effect Analysis (FMEA)}

With a wide definition, FMEA is a systematic approach to evaluate a process, system, design, or service to explore in which way failures can occur [22]. The method may be applied to reveal shortcomings of an ongoing process or risks on a design of a product in the development phase. The method has originated in a Military Procedure of the United States Department of Defense with some shortcomings [23]. It has been widely applied to many National Aeronautics and Space Administration (NASA) space programs [24]. Today, FMEA has many applications in manufacturing industries. It is among the most powerful tools to determine the lack of a product design or production process. Maddalena et al. applied DFMEA in the feasibility phase of Automotive CMOS Image Sensors development [25]. Klochkov et al. assessed the process of can stock production by a detailed PFMEA [26]. Since there are numerous studies, many literature review papers can be encountered in the literature. Sharma and Srivastava surveyed FMEA methods with a scope basis and included many studies and their contributions [27]. Spreafico et al have introduced a state-of-the-art survey of 220 papers and supported the review with 109 relevant patent information [28]. Huang et al. represented a systematic literature review and gave insights regarding the future of FMEA [29]. Ng et al. provided information on a more capable deployment of FMEA by integrating to other tools such as inventive problem-solving methodology (TRIZ), Quality Function Deployment (QFD), and Root Cause Analysis (RCA) [30].

Combining our literature review on Machine Vision-based Quality control and FMEA discloses that there is a lack of integrating DFMEA and PFMEA at the application level. According to our research, we have not found any research about combining PFMEA and DFMEA. DFMEA reflects the risks on the product design where PFMEA helps to manage risks on the manufacturing of a product. As a contribution of this study, combining both FMEAs provides a more robust insight to determine the most critical risks on the quality of the produced product since the combination contains both risks that can be met on product and risks that can be occurred during the production of the product. Another originality is the representation of both DFMEA and PFMEA in a common FMEA table. 


\section{PROPOSED METHODOLOGY}

The firm AN-EL A.S. is an electromechanics component producer for household appliances in Turkey. Rotary Switch in Figure 1 is a wide product family which is manufactured by AN-EL A.S. and sold to household appliance producers especially to be assembled to cooking devices. Since the firm exports 85 percent of products to worldwide plants, especially to global production sites, the quality of the final product has utmost importance for a sustainable commercial relationship.

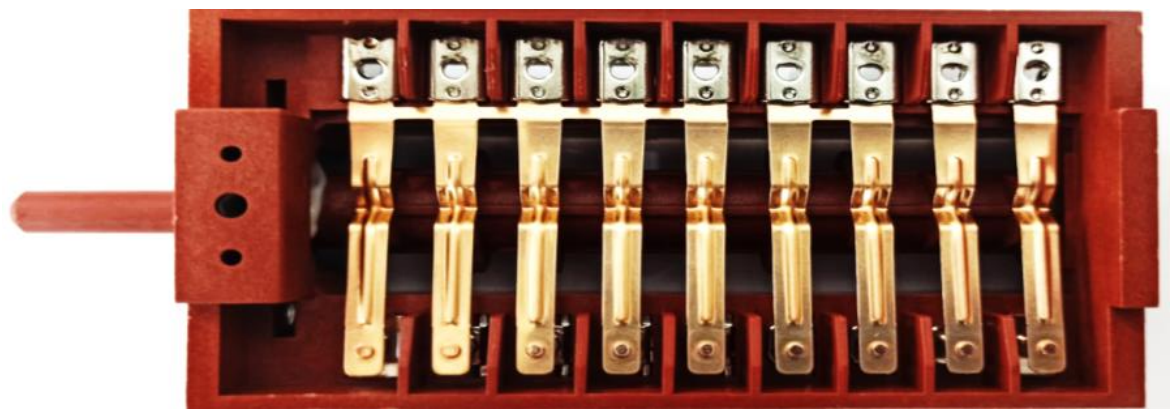

Figure 1. Rotary Switch (Bottom View)

Table 1. Severity, Probability, and Detectability Criteria

\begin{tabular}{|c|c|c|c|}
\hline Rank & Severity & Probability & Detectability \\
\hline 10 & $\begin{array}{l}\text { May endanger machine or assembly operator. Very high } \\
\text { severity ranking when a potential failure mode affects } \\
\text { safe product operation and/or involves noncompliance } \\
\text { with regulations without a warning. }\end{array}$ & $\begin{array}{l}\geq 100 \text { per thousand } \\
(1,000) \text { pieces } \\
\geq 1 \text { in } 10\end{array}$ & $\begin{array}{c}\text { Absolute certainty of } \\
\text { non-detection. }\end{array}$ \\
\hline 9 & $\begin{array}{l}\text { May endanger machine or assembly operator. Very high } \\
\text { severity ranking when a potential failure mode affects } \\
\text { safe product operation and/or involves noncompliance } \\
\text { with regulations with a warning. }\end{array}$ & $\begin{array}{l}50 \text { per thousand } \\
(1.000) \text { pieces } \\
1 \text { in } 20\end{array}$ & $\begin{array}{c}\text { Controls will probably } \\
\text { not detect. }\end{array}$ \\
\hline 8 & $\begin{array}{l}\text { Major disruption to the production line. Product/item } \\
\text { inoperable (loss of primary function). } 100 \% \text { of products } \\
\text { should be scrapped. }\end{array}$ & $\begin{array}{c}20 \text { per thousand } \\
(1.000) \text { pieces } \\
1 \text { in } 50\end{array}$ & $\begin{array}{l}\text { Controls may } \\
\text { seldomly detect. }\end{array}$ \\
\hline 7 & $\begin{array}{l}\text { Minor disruption to the production line. Product/item } \\
\text { operable but at a reduced level of performance. Customer } \\
\text { very dissatisfied. A high portion of the product should be } \\
\text { scrapped. }\end{array}$ & $\begin{array}{l}10 \text { per thousand } \\
(1.000) \text { pieces } \\
1 \text { in } 100\end{array}$ & $\begin{array}{l}\text { Controls have a poor } \\
\text { chance of detection. }\end{array}$ \\
\hline 6 & $\begin{array}{l}\text { Minor disruption to the production line. } \\
\text { Product/item operable but Convenience/Feature item(s) } \\
\text { inoperable. Customer dissatisfied. A low portion of the } \\
\text { product should be scrapped. }\end{array}$ & $\begin{array}{l}2 \text { per thousand } \\
(1.000) \text { pieces } \\
1 \text { in } 500\end{array}$ & $\begin{array}{l}\text { Controls may detect } \\
\text { case by case. }\end{array}$ \\
\hline 5 & $\begin{array}{l}\text { Minor disruption to the production line. } \\
\text { Product/item operable but Convenience/Feature item(s) } \\
\text { operable at a reduced level of performance. } \\
\text { The product should be sorted and reworked. }\end{array}$ & $\begin{array}{c}1 \text { per thousand } \\
(1.000) \text { pieces } \\
1 \text { in } 1.000\end{array}$ & Controls may detect. \\
\hline 4 & $\begin{array}{l}\text { Minor disruption to the production line. } \\
\text { Fit and Finish/Squeak and Rattle item does not conform. } \\
\text { Defect noticed by most customers (greater than } 75 \% \text { ). } \\
\text { The product should be sorted, and a high portion should } \\
\text { be reworked. }\end{array}$ & $\begin{array}{c}0.5 \text { per thousand } \\
(1.000) \text { pieces } \\
1 \text { in } 2.000\end{array}$ & $\begin{array}{l}\text { Controls may have a } \\
\text { good chance to detect. }\end{array}$ \\
\hline 3 & $\begin{array}{l}\text { Minor disruption to the production line. } \\
\text { Fit and Finish/Squeak and Rattle item does not conform. } \\
\text { Defect noticed by } 50 \% \text { of customers. The product should } \\
\text { be sorted, and a moderate portion should be reworked. }\end{array}$ & $\begin{array}{c}0.1 \text { per thousand } \\
(1.000) \text { pieces } \\
1 \text { in } 10.000\end{array}$ & $\begin{array}{l}\text { Controls have a good } \\
\text { chance to detect. }\end{array}$ \\
\hline 2 & $\begin{array}{l}\text { Minor disruption to the production line. } \\
\text { Fit and Finish/Squeak and Rattle item does not conform. } \\
\text { Defect noticed by discriminating customers (less than } \\
\text { 25\%). The product should be sorted, and a low portion } \\
\text { should be reworked. }\end{array}$ & $\begin{aligned} \leq & 0.1 \text { per thousand } \\
& (1.000) \text { pieces }\end{aligned}$ & $\begin{array}{l}\text { Controls almost } \\
\text { certain to detect. }\end{array}$ \\
\hline
\end{tabular}




\begin{tabular}{|c|c|c|c|}
\hline 1 & No effect. & $\begin{array}{c}\text { Failure is eliminated } \\
\text { through preventative } \\
\text { control }\end{array}$ & $\begin{array}{c}\text { Controls certain to } \\
\text { detect. }\end{array}$ \\
\hline
\end{tabular}

The rotary switch can be produced by assembling multiple semi-products in a production line. Most of the parts are sensitive to external factors such as humidity and pressure. Hence, an intense production process is required to acquire precise final products. Such a process requires continuous improvement actions to assure a high level of quality. An appropriate way to ensure this quality is periodically analyzing the product and production process with analytical tools.

Table 2. PFMEA for Rotary Switch Production

\begin{tabular}{|c|c|c|c|c|c|c|c|}
\hline $\begin{array}{l}\text { Process } \\
\text { Step }\end{array}$ & $\begin{array}{l}\text { Failure } \\
\text { Mode }\end{array}$ & Failure Effect & Sev. & Prob. & Det. & RPN & Prevention/Action \\
\hline $\begin{array}{c}\text { Assembly } \\
\text { of Moving } \\
\text { Terminals } \\
\text { by Press }\end{array}$ & $\begin{array}{l}\text { Wrong } \\
\text { Sequence }\end{array}$ & $\begin{array}{l}\text { Wrong } \\
\text { functionality, } \\
\text { should be } \\
\text { scrapped }\end{array}$ & 9 & 5 & 4 & 180 & $\begin{array}{l}\text { - Increasing the number of workers for } \\
\text { control } \\
\text { - A Poka-Yoke Device that checks the } \\
\text { sequence electrically. } \\
\text { - A Machine Vision supported Poka-Yoke } \\
\text { device }\end{array}$ \\
\hline $\begin{array}{c}\text { Assembly } \\
\text { of Moving } \\
\text { Terminals } \\
\text { by Press }\end{array}$ & $\begin{array}{l}\text { Wrong } \\
\text { types of } \\
\text { moving } \\
\text { terminal }\end{array}$ & $\begin{array}{l}\text { Wrong } \\
\text { functionality, } \\
\text { should be } \\
\text { scrapped }\end{array}$ & 9 & 5 & 3 & 135 & $\begin{array}{l}\text { - Increasing the number of workers for } \\
\text { control } \\
\text { - A Poka-Yoke Device that checks the } \\
\text { sequence electrically. } \\
\text { - A Machine Vision supported Poka-Yoke } \\
\text { device }\end{array}$ \\
\hline $\begin{array}{c}\text { Assembly } \\
\text { of Fixed } \\
\text { Terminals } \\
\text { by Press }\end{array}$ & $\begin{array}{l}\text { Wrong } \\
\text { types of } \\
\text { fixed } \\
\text { terminal }\end{array}$ & $\begin{array}{l}\text { Wrong } \\
\text { functionality, } \\
\text { should be } \\
\text { scrapped }\end{array}$ & 6 & 5 & 3 & 90 & $\begin{array}{l}\text { - Increasing the number of workers for } \\
\text { control } \\
\text { - A Poka-Yoke Device that checks the } \\
\text { sequence electrically. } \\
\text { - A Machine Vision supported Poka-Yoke } \\
\text { device }\end{array}$ \\
\hline $\begin{array}{l}\text { Pressing } \\
\text { Fixed } \\
\text { Terminals }\end{array}$ & $\begin{array}{c}\text { Missing } \\
\text { Number of } \\
\text { Fixed } \\
\text { Terminals }\end{array}$ & $\begin{array}{l}\text { Wrong } \\
\text { functionality, } \\
\text { should be } \\
\text { reworked }\end{array}$ & 7 & 4 & 3 & 84 & $\begin{array}{l}\text { - Can be checked visually before pressing } \\
\text { - A Machine Vision supported Poka-Yoke } \\
\text { device } \\
\text { - Missing terminals should be pressed }\end{array}$ \\
\hline $\begin{array}{l}\text { Camshaft } \\
\text { integration }\end{array}$ & $\begin{array}{l}\text { Use of the } \\
\text { wrong } \\
\text { camshaft }\end{array}$ & $\begin{array}{c}\text { Wrong } \\
\text { functionality, } \\
\text { should be } \\
\text { reworked }\end{array}$ & 7 & 3 & 3 & 63 & $\begin{array}{l}\text { - Can be checked visually before pressing } \\
\text { - A Poka-Yoke Device for functionality test } \\
\text { - Eliminating different types of the camshaft } \\
\text { from the feeder with an additional process } \\
\text { - Camshaft should be reassembled. }\end{array}$ \\
\hline $\begin{array}{l}\text { Nut } \\
\text { assembly }\end{array}$ & $\begin{array}{l}\text { Mis- } \\
\text { assembly of } \\
\text { nuts to body }\end{array}$ & $\begin{array}{l}\text { Switch cannot } \\
\text { be assembled to } \\
\text { main appliance }\end{array}$ & 5 & 4 & 3 & 60 & $\begin{array}{l}\text {-Can be checked by the operator. } \\
\text { - A Poka-Yoke device for alignment. }\end{array}$ \\
\hline $\begin{array}{c}\text { Press of } \\
\text { Fixed } \\
\text { Terminals }\end{array}$ & $\begin{array}{l}\text { Low } \\
\text { pressing } \\
\text { pressure }\end{array}$ & $\begin{array}{c}\text { Loose } \\
\text { terminals, risk } \\
\text { of removal }\end{array}$ & 6 & 3 & 3 & 54 & $\begin{array}{l}\text { - Can be checked with a pneumatic device } \\
\text { - Terminals should be pressed again. }\end{array}$ \\
\hline $\begin{array}{l}\text { Protective } \\
\text { Cover } \\
\text { Assembly }\end{array}$ & $\begin{array}{l}\text { Missing } \\
\text { Cover }\end{array}$ & $\begin{array}{l}\text { Moving } \\
\text { terminals may } \\
\text { be harmed }\end{array}$ & 7 & 3 & 2 & 42 & $\begin{array}{l}\text { - Visual control by the operator } \\
\text { - Machine vision supported Poka-Yoke } \\
\text { device }\end{array}$ \\
\hline
\end{tabular}




\begin{tabular}{|c|c|c|c|c|c|c|c|}
\hline $\begin{array}{c}\text { Assembly } \\
\text { of Spring }\end{array}$ & $\begin{array}{c}\text { Wrong } \\
\text { spring } \\
\text { selection }\end{array}$ & $\begin{array}{c}\text { Rotation torque } \\
\text { may differ }\end{array}$ & 4 & 3 & 3 & 36 & $\begin{array}{l}\text {-Can be checked with a Torque meter. } \\
\text { - A Poka-Yoke device with torque } \\
\text { measurement capability. }\end{array}$ \\
\hline $\begin{array}{c}\text { D Profile } \\
\text { Assembly }\end{array}$ & $\begin{array}{c}\text { Unoriented } \\
\text { D Profile } \\
\text { angle }\end{array}$ & $\begin{array}{c}\text { Bad visual } \\
\text { effect for final } \\
\text { customer }\end{array}$ & 4 & 3 & 3 & 36 & $\begin{array}{l}\text { - Can be checked visually by the operator. } \\
\text { measurement capability. }\end{array}$ \\
\hline $\begin{array}{c}\text { Nut } \\
\text { Assembly }\end{array}$ & $\begin{array}{c}\text { Missing } \\
\text { Nuts }\end{array}$ & $\begin{array}{c}\text { Switch cannot } \\
\text { be assembled to } \\
\text { main appliance }\end{array}$ & 5 & 2 & 2 & 20 & $\begin{array}{l}\text {-Can be checked by the operator. } \\
\text { - A Poka-Yoke device for nut control. }\end{array}$ \\
\hline
\end{tabular}

One of the most important tools for these analyses is FMEA. The classical FMEA process with Severity, Probability, and Detectability criteria is applied to determine the most critical risks. Severity, Probability, and Detectability determining criteria for this study are shown in Table 1 . The criteria in Table 1 have been prepared in line with the FMEA Handbook by Automotive Industry Action Group (AIAG) [31].

Upon identifying the scores of each risk, the Risk Priority Number (RPN) should be calculated with the formula in Equation 1 as the product of Severity, Probability, and Detectability [31]. An RPN value may change between 1 and 1.000 since Severity, Occurrence, and Detection may take values between 1 and 10.

$$
\text { RPN = Severity } x \text { Occurrence } x \text { Detection }
$$

Table 2 contains the risks of the production process by scoring their severity, probability, and detectability scores, failure mode, possible effect, and preventive actions. The PFMEA list has been sorted in descendant order concerning RPN values.

Table 3 indicates five items of DFMEA. The remarkable point for both DFMEA and PFMEA is having the risks for moving terminal on the top of the list. Since the FMEA items are recalculated in the Results section after integration of the proposed system, selected action and results are not included in Table 2 and Table 3.

Table 3. DFMEA for Rotary Switch Production

\begin{tabular}{|c|c|c|c|c|c|c|c|}
\hline $\begin{array}{c}\text { Related } \\
\text { Part }\end{array}$ & Failure Mode & Failure Effect & Sev. & Prob. & Det. & RPN & Prevention/Action \\
\hline $\begin{array}{c}\text { Moving } \\
\text { Terminal }\end{array}$ & $\begin{array}{c}\text { Deformed } \\
\text { moving } \\
\text { terminal } \\
\text { Aunctionality, } \\
\text { should be } \\
\text { scrapped }\end{array}$ & 8 & 4 & 5 & 160 & $\begin{array}{l}\text { Avoiding } \\
\text { Poka-Yoke device }\end{array}$ \\
\hline $\begin{array}{c}\text { Switch } \\
\text { Body }\end{array}$ & $\begin{array}{c}\text { Soft housing } \\
\text { for terminals }\end{array}$ & $\begin{array}{c}\text { The terminal } \\
\text { may be } \\
\text { removed }\end{array}$ & 8 & 3 & 3 & 72 & $\begin{array}{l}\text { - A new selection process for } \\
\text { deformed terminals }\end{array}$ \\
\hline $\begin{array}{c}\text { Switch } \\
\text { Body / } \\
\text { Terminal }\end{array}$ & $\begin{array}{c}\text { Incompatible } \\
\text { tolerances }\end{array}$ & $\begin{array}{c}\text { Inappropriate } \\
\text { assembly of } \\
\text { terminals }\end{array}$ & 6 & 4 & 3 & 72 & $\begin{array}{l}\text { - New raw material mixture for a } \\
\text { harder body }\end{array}$ \\
\hline
\end{tabular}




\begin{tabular}{|c|c|c|c|c|c|c|c|}
\hline $\begin{array}{c}\text { D Profile } \\
\text { Assembly }\end{array}$ & $\begin{array}{c}\text { Size based } \\
\text { assembly } \\
\text { problem }\end{array}$ & $\begin{array}{c}\text { Cannot } \\
\text { assembly D } \\
\text { Profile }\end{array}$ & 5 & 3 & 4 & 60 & $\begin{array}{l}\text { - Update tolerances on mold } \\
\text { - Use of cutters for reducing size } \\
\text { on non-conforming D profiles. }\end{array}$ \\
\hline $\begin{array}{c}\text { All } \\
\text { Plastics }\end{array}$ & $\begin{array}{c}\text { Observation } \\
\text { of burr }\end{array}$ & Visual & 4 & 4 & 2 & 32 & $\begin{array}{l}\text { - Can be perceived as a quality } \\
\text { problem by customers. } \\
\text { - Burrs should be removed. } \\
\text { - Update on mold design. }\end{array}$ \\
\hline
\end{tabular}

Moving terminals that are used for this production have various types as shown in Figure 2. According to DFMEA and PFMEA analysis, the quality requirements in concern of this study consist of the use of correct types, correct sequence, and correct assembly of moving terminals that don't have any deformation.

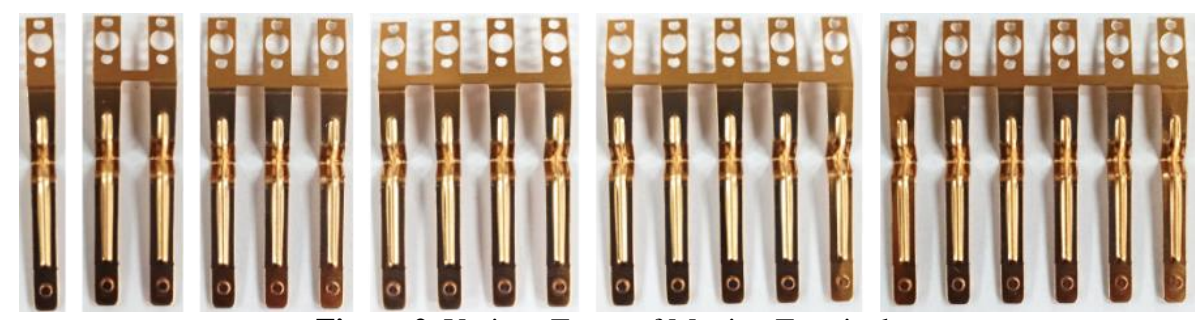

Figure 2. Various Types of Moving Terminals

Pareto Analysis has been completed by aggregating both PFMEA and DFMEA risks in descending order according to their RPN values and selecting the most critical risks in concern. Three out of 16 risks have been selected upon evaluation of the Pareto Chart in Figure 3 which have distinctly higher values compared to the remaining risks and are equal to nearly 20 percent $(16$ x $20 \%=3.2)$ of the total risks.

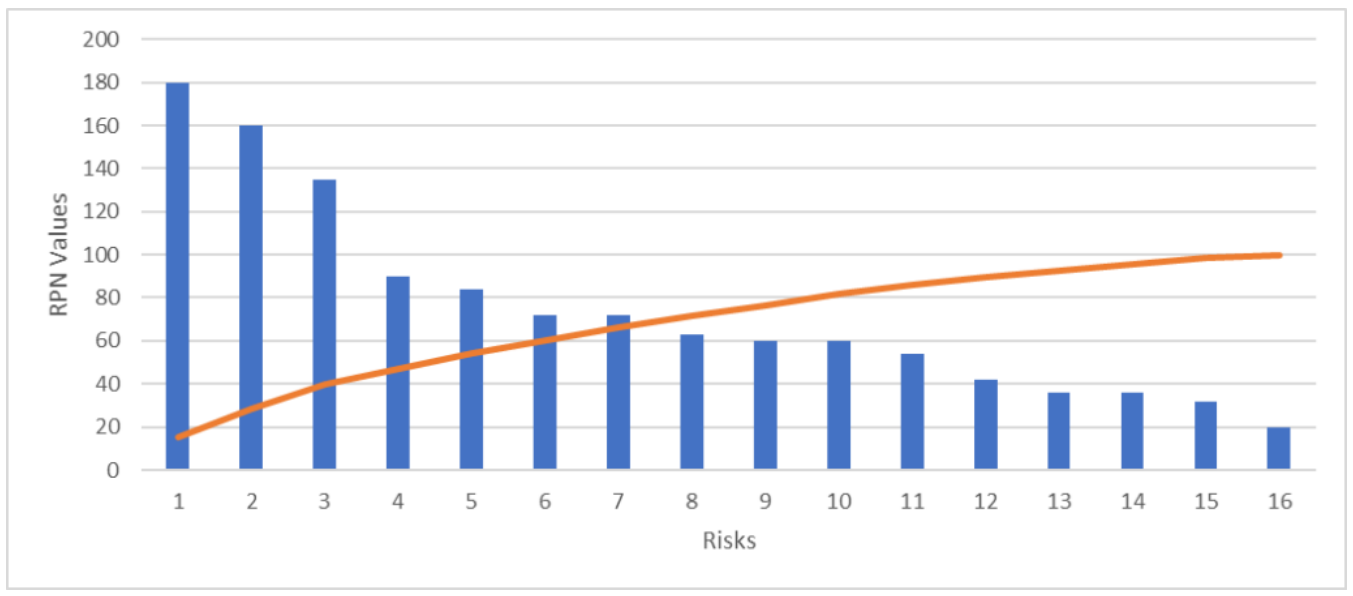

Figure 3. Pareto Analysis Chart of RPN Values of DFMEA and PFMEA

Selected risks that have a high impact on quality prove that the most critical items in the process are moving terminals. This conclusion is not surprising since moving terminals are assembled to the body of the rotary switch by an irreversible pressing operation. Moving terminals cannot be removed from the body after pressing, hence any failure results in a scrap of body and moving terminals. Moving terminals are the most expensive components among semi-products. Scrapping moving terminals and body sources a burdensome quality cost to the whole production. 
Severity over 8 should be handled carefully. Since severity cannot be improved without design modification, a process enhancement is intended to improve probability and detectability values. The most common suggestion is to avoid risks with mistake-proofing (Poka-Yoke) [32]. The final decision to avoid any production risks has been determined as integrating a Poka-Yoke device into the production line. After evaluating several alternatives, the conclusion was developing a machine vision-supported Poka-Yoke Device. To achieve this quality control capability by machine vision, multiple low-cost alternatives are examined. Raspberry Pi-4 has been selected to provide sufficient computational power. Raspberry Pi-4 has been integrated into a touch screen as shown in Figure 4.

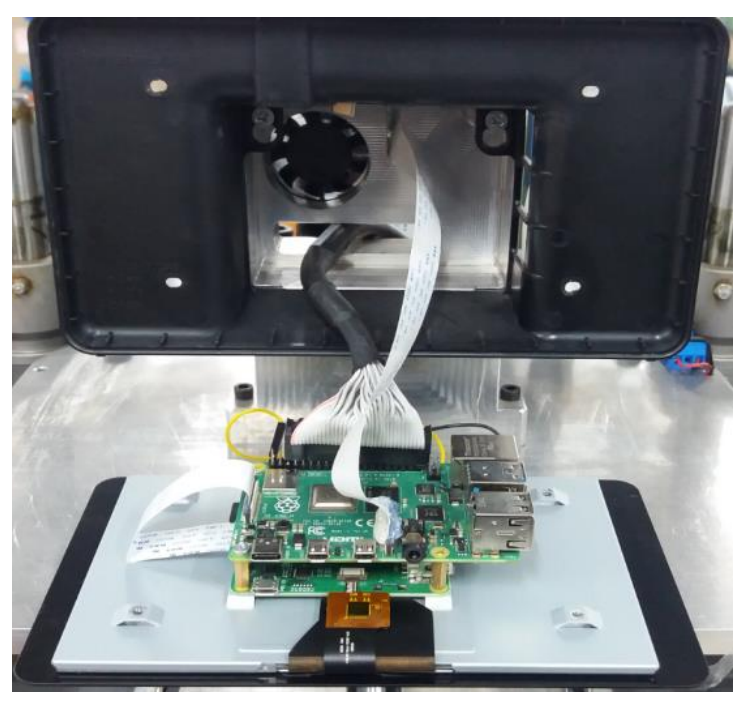

Figure 4. Inner Structure of the System

The configuration for the optical quality control system has been completed by adding lighting, camera, and interfaces. The resulting system is demonstrated in Figure 5. The new system is designed to be operated by a single operator. Additionally, the system can check two rotary switches simultaneously. Helping to increase the accuracy of the classification, it is also intended to decrease the processing time of the control since there has been detected a bottleneck for the process.

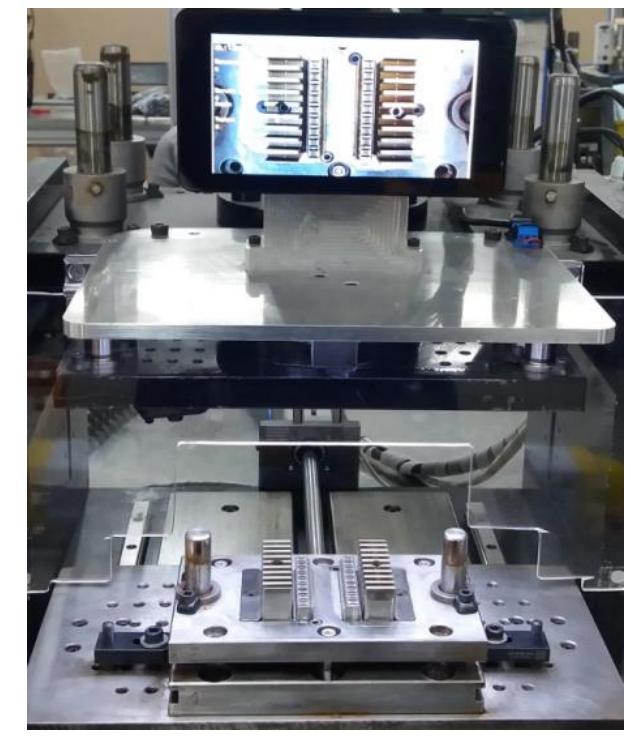

Figure 5. Integrated Quality Control System to Check Moving Terminals 
Image operations of this process are conducted via OpenCV. A single switch has 9 circuit lines on its body. Analyzing the construction and alternatives of the combinations, it has been determined that 4 features for each line suffice to determine the type and the condition of the moving terminal. Additional 8 features between lines help to determine if a shunt exists between two adjacent lines. A total of 44 discrete lines on the rotary switches are checked during the image processing phase for robust classification. These lines are indicated in Figure 6 with blue color including their enumeration.

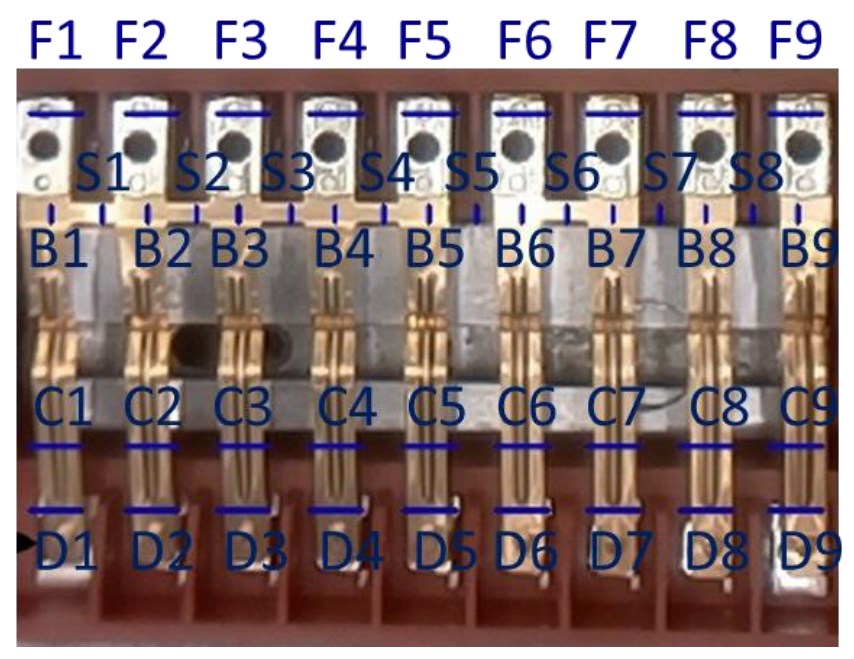

Figure 6. 44 Features on Rotary Switch for Classification

The feature points in Figure 6 are used to determine the type of the terminal and the connection between each terminal. Possible 6 types of terminal alternatives are shown in Figure 7. From left to right, the first line has a complete moving terminal with a fixed terminal on the opposite side, the second line has a semi terminal, the third line has a shunt that is used to connect to adjacent terminals, the fourth line has only a fixed terminal on the opposite side, the fifth line has a semi terminal that has a fixed terminal on the opposite side, and the sixth line has a shunt that has a fixed terminal on the opposite side.

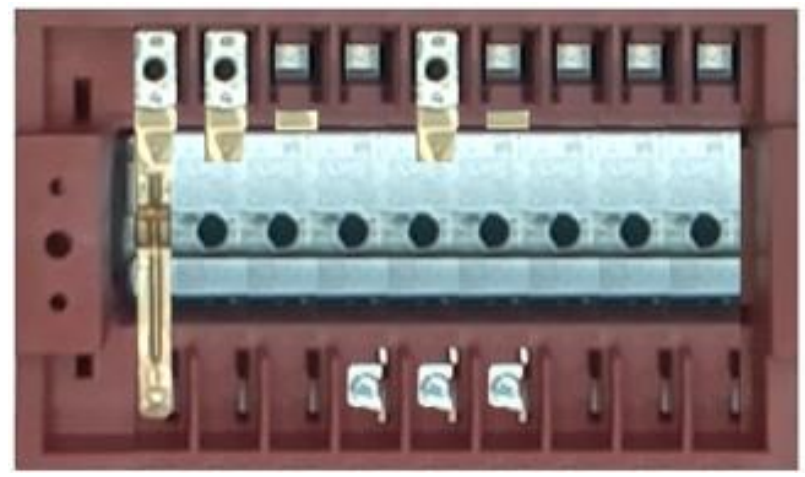

Figure 7. Types of the Possible Terminals

The types of terminals have been enumerated from 1 to 6 from left to right. If the line contains no terminals, the type is valued with 0 . The connection between terminals is also considered to have the value 1 if there is a shunt between two adjacent terminals, 0 otherwise. Hence, a vector with size 9 can identify the terminals on the lines while a vector with size 8 can define the connections between terminals. The combined vector with 17 digits can define the connection type of a rotary switch.

The existence of metal parts can be detected and evaluated according to RGB values. The target variable for the classification algorithm is the connection vector with 44 digits which is converted according to the connection vector with 17 digits. The digit of the target variable is 0 if the feature should be metal 
and 0 if otherwise. 9 digits of the connection vector can take the values from 0 to 7 . The last 8 digits are binaries with 0 and 1 . Hence the number of possible connection types is over 10 billion. Supplying the RGB values of 44 points to the classification algorithm enables it to determine the connection vector. The vector has been compared to the actual vector as training data. To achieve a smooth image processing process, a LED lighting has been mounted on the rotary switches in the line. Hence, a better contrast between plastic and metal parts can be acquired, since metal parts shine under lighting where plastic parts remain dark. 3.500 trials have been carried out to train classification algorithm on threshold values over which it is assessed that the underlying surface is metal with a smooth form. It has been also assured by lighting that the RGB values of deformed metal parts also remain below the threshold value. Most bright RGB value in feature lines has been selected for further evaluations on metal component existence. Figure 8 summarizes the overall process.

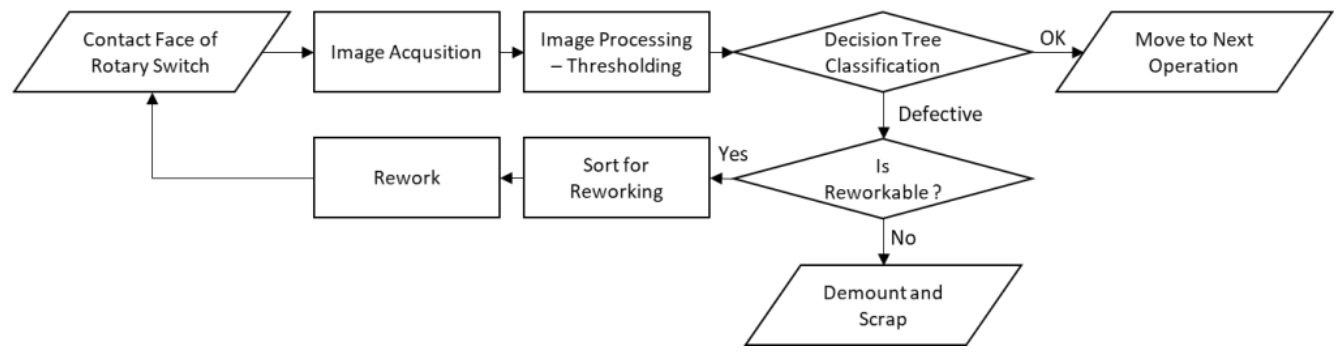

Figure 8. Machine Vision Supported Quality Control Process Flow

The classification algorithm suggests the threshold intervals for RGB values for each vector as in Table 4 where $\mathrm{X}$ is the clusters of numbers from 1 to 9 for $\mathrm{F}, \mathrm{B}, \mathrm{C}$, and $\mathrm{D}$, from 0 to for $\mathrm{S}$.

Table 4. RGB Threshold values for Metal Detection

\begin{tabular}{cccc} 
VectorlComponent & Red & Green & Blue \\
\hline FX & $(140,255)$ & $(110,255)$ & $(110,255)$ \\
SX & $(155,255)$ & $(120,255)$ & $(110,255)$ \\
BX & $(155,255)$ & $(120,255)$ & $(110,255)$ \\
CX & $(115,255)$ & $(110,255)$ & $(95,255)$ \\
DX & $(150,255)$ & $(130,255)$ & $(130,255)$
\end{tabular}

CART classification algorithm has been applied in this study since the algorithm is capable of handling binary parameters and variables. Providing RGB values of 44 features, the algorithm predicts the connection type of the rotary switch with a 17-digit vector. During the real production phase, The operator is informed about the prediction of the classification algorithm via touch screen as shown in Figure 9. For defective parts, additional information on defect points is highlighted with an enumeration to inform defective points on the rotary switch.
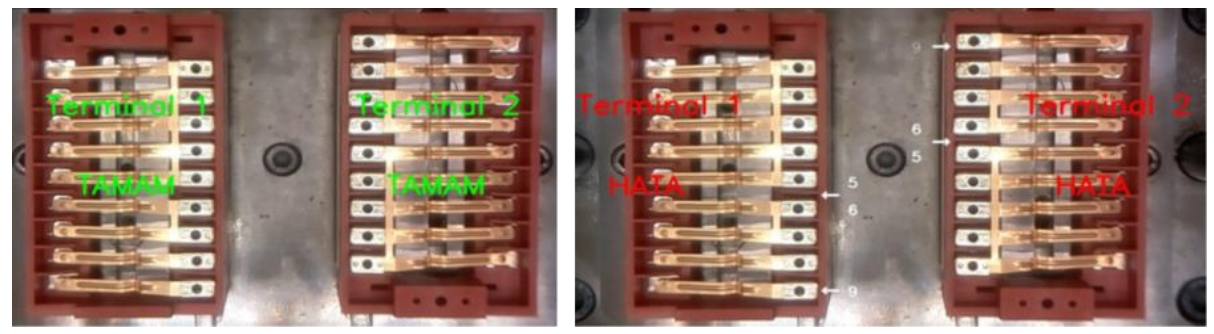

Figure 9. Pass Warning (on the left) and Defective Warning (on the right) by System 


\section{RESULTS AND DISCUSSION}

5.000 rotary switches have been allocated for training, validation, and test of the classification algorithm. Rotary switches were processed by both human operators and the proposed system. To enhance the accuracy of the process, two operators have been visually checking for defects before the installation of the system. Hence, the accuracy of the operators shows the result of classification by two consecutive control of two operators. The main classification error of operators is the false identification of defective switches. More clearly, the operators usually could not detect defects on rotary switches. Since the switch is safety-critical, any "defective" identification by any of the operators results to classify the switch as "defective". We have checked the reliability of the decisions of operators with Kappa Statistics [33]. Table 5 includes the classifications by both operators concerning the condition of 5.000 rotary switches.

Table 5. Classification Matrix of Human Operators

\begin{tabular}{|l|c|c|c|}
\cline { 3 - 4 } \multicolumn{2}{|c|}{} & \multicolumn{2}{c|}{ Operator 2 } \\
\cline { 3 - 4 } \multicolumn{2}{c|}{ Accept } & Defect \\
\hline \multirow{2}{*}{ Operator 1 } & Accept & 4244 & 193 \\
\cline { 2 - 4 } & Defect & 199 & 364 \\
\hline
\end{tabular}

Considering the rates in Table 5, Kappa Statistics has been calculated according to the formula in Equation 2,

$$
\kappa=\frac{p_{o}-p_{e}}{1-p_{e}}
$$

where $\kappa$ is the Kappa statistics, $p_{o}$ is the observed agreement between operators, $p_{e}$ is the hypothetical probability of chance agreement. The scale for Kappa Statistics [34] in Table 6 suggests the current classification performance of operators results in substantial agreement with a Kappa value of $61 \%$.

Table 6. Agreement Scale for Kappa Statistics

$\begin{array}{ll}\frac{\text { Kappa }}{<0} & \underline{\text { Agreement }} \\ 0.01-0.20 & \text { Less than chance agreement } \\ 0.21-0.40 & \text { Faight agreement } \\ 0.41-0.60 & \text { Moderate agreement } \\ 0.61-0.80 & \text { Substantial agreement } \\ 0.81-1.00 & \text { Almost perfect agreement }\end{array}$

The results in Table 7 prove that the proposed methodology and system improve the process by nearly 1 percent compared to the cumulative classification performance of both operators which cannot be ignored where defects are evaluated with dppm rates. Support Vector Machine (SVM) classification method has been also applied for benchmarking the proposed Decision Tree Algorithm. The results show that the proposed algorithm performs better both in the means of accuracy and runtime. For image processing, Canny Edge detection on the binarized image has been tried to be classified to compare our proposed methodology. The matching accuracy on a single image did not pass the level of 91 percent. Therefore, five images per classification have been tried to increase accuracy. The accuracy could only catch an average of 95 percent and the average runtime increased to 4.5 seconds. Besides, the match difference between 
defective and acceptable rotary switches had a very low resolution with an average of 1 percent. The method was ignored for further evaluation.

Table 7. Results of The Classification Process

\begin{tabular}{ccccccc}
$\begin{array}{c}\text { Type of } \\
\text { Data }\end{array}$ & $\begin{array}{c}\text { \# of } \\
\text { Items }\end{array}$ & $\begin{array}{c}\text { Accuracy of } \\
\text { Operators }\end{array}$ & $\begin{array}{c}\text { Accuracy } \\
\text { of Decision } \\
\text { Tree }\end{array}$ & $\begin{array}{c}\text { Average } \\
\text { Runtime of } \\
\text { Decision Tree }\end{array}$ & $\begin{array}{c}\text { Accuracy } \\
\text { of SVM }\end{array}$ & $\begin{array}{c}\text { Average } \\
\text { Runtime } \\
\text { of SVM }\end{array}$ \\
\hline Training & 3500 & $98,80 \%$ & $99,98 \%$ & $140 \mathrm{~ms}$ & 97,08 & $1,316 \mathrm{sec}$ \\
Validation & 750 & $98,53 \%$ & $99,46 \%$ & $135 \mathrm{~ms}$ & 95,88 & $1,418 \mathrm{sec}$ \\
Test & 750 & $98,40 \%$ & $99,60 \%$ & $135 \mathrm{~ms}$ & 96,14 & $1,395 \mathrm{sec}$
\end{tabular}

Apart from featuring aspects like cost, integrability, simplicity, accessibility, etc, the proposed system should be also compared to similar systems for its performance concerning accuracy and runtime. Several similar studies have been also compared to the proposed methodology. The proposed classification algorithms by Chauhan and Surgenor [35] uses motions instead of images on a high-speed O-ring assembly line. Although having the processing power of a PLC behind, the fastest algorithm requires 5.88 seconds to process a 10-seconds video which exceeds the limit for the cycle of operation in rotary switch production line. The system should receive a defective or acceptable signal before fixing the moving terminals. Hence, it can be assessed that motion analysis for defect detection would have a risk to create a bottleneck on the production line. In another study by Kunakornvong and Sooraksa [36], the assembly of the Air Bearing Surface (ABS) is controlled via a Machine Vision System on a Hard Disk Drive (HDD). With the help of an industrial camera and industrial PC with Intel Core 77 CPU, they process the surface image of a DD by detecting defects with Fuzzy Dynamic Histogram Equalization. The average runtime for the proposed system is 2 seconds on the industrial PC. Shen et al. [37] developed a machine vision system to check defects of bearings. Their Support Vector Machine (SVM) based methodology provides also nearly 99 percent accuracy without including the runtime information. The image processing algorithm checks the smoothness and text on the body of the bearing. Edinbarough et al [38] suggested an inspection system that controls IC of PCB with a Neural Network-based algorithm. Without providing exact runtime, they provide training time as $8-20$ minutes and 99 percent accuracy for classification.

It can be deducted from the survey that many studies focus on providing detailed information on algorithms avoiding to include runtime or accuracy statistics. As another aspect, the performance may drastically change depending on the aim of the application, required results, software and hardware environment, the number of features, type of classification, and image processing algorithms. Hence, it is assessed that the best way for developing an effective is trying to achieve the required accuracy with the simplest possible algorithm.

After integrating the visual system into the manufacturing system, the production process has been observed for one month to have more concrete results. RPN values for the risks have been updated as shown in Table 8 after attaining a stable process. Severity value could not be updated since the design of the product has not been changed. Better probability and detectability scores provided from the proposed system helped to improve overall RPN scores of the corresponding risks.

Table 8. Updated FMEA Items

\begin{tabular}{|c|c|c|c|c|c|c|c|}
\hline P/D & $\begin{array}{c}\text { Process } \\
\text { Step/Related } \\
\text { Part }\end{array}$ & $\begin{array}{c}\text { Failure } \\
\text { Mode }\end{array}$ & Failure Effect & Sev. & Prob. & Det. & RPN \\
\hline P & $\begin{array}{c}\text { Assembly of } \\
\text { Moving } \\
\text { Terminals by } \\
\text { Press }\end{array}$ & $\begin{array}{c}\text { Wrong } \\
\text { Sequence }\end{array}$ & $\begin{array}{c}\text { Wrong electrical } \\
\text { functionality, should } \\
\text { be scrapped }\end{array}$ & 9 & 3 & 2 & $\mathbf{5 4}$ \\
\hline
\end{tabular}




\begin{tabular}{|c|c|c|c|c|c|c|c|}
\hline $\mathrm{P}$ & $\begin{array}{c}\text { Assembly of } \\
\text { Moving } \\
\text { Terminals by } \\
\text { Press }\end{array}$ & $\begin{array}{c}\text { Wrong } \\
\text { types of } \\
\text { moving } \\
\text { terminal }\end{array}$ & $\begin{array}{c}\text { Wrong electrical } \\
\text { functionality, should } \\
\text { be scrapped }\end{array}$ & 9 & 2 & 2 & $\mathbf{3 6}$ \\
\hline $\mathrm{D}$ & $\begin{array}{c}\text { Moving } \\
\text { Terminal }\end{array}$ & $\begin{array}{c}\text { Deformed } \\
\text { moving } \\
\text { terminal }\end{array}$ & $\begin{array}{c}\text { Avoiding } \\
\text { functionality, should } \\
\text { be scrapped }\end{array}$ & 8 & 2 & 2 & $\mathbf{3 2}$ \\
\hline
\end{tabular}

The presentation of the P/D column in the FMEA table is another contribution of this study, where $\mathrm{P}$ stands for Process and D stands for Design. Hence, both Design and Process items can be displayed in the same table without any confusion. Although not changing the severity, a new Poka-Yoke Device helped to improve Probability and Detection values.

\section{CONCLUSION}

With technological improvements, the number of cost-effective systems in the industry has been drastically increased to provide benefits on quality costs. In this study, a Raspberry Pi-based low-cost Machine Vision System that is integrated into a rotary switch manufacturing system has been presented. The system was installed to detect the type, sequence, and form defects of moving terminals before pressing on the rotary switch body. Hence, the scrap of the rotary switch was avoided by detecting the failure before pressing which is an irreversible process.

Results show that the vector inquired by thresholding and binarization operations on the image of the rotary switch was sufficient to compare default values and detect defects. Raspberry Pi-operated OpenCV software can provide the vector accurately under appropriate lighting. Classification algorithm coded on Python improves the quality control process early 1 percent compared to human operators with regards to training, validating, and testing results. 1 percent improvement on the quality control process cannot be ignored where the defect of the product is calculated with dppm level. Additionally, the same process can be completed with one operator instead of two.

The distinguishing part of the study is a combination of PFMEA and DFMEA analysis. To the best of the authors' knowledge, this is the first study that applies both PFMEA and DFMEA to determine the improvements in the quality of a manufacturing system. Another originality is the new "P/D" column for FMEA analysis which distinguishes the FMEA items as "Process" or "Design". In this way, both Process and Design items may be displayed in the same FMEA table without any confusion. During FMEA analysis, failure modes scored according to Severity, Probability, and Detectability dimensions. For future study, a new dimension as "Scope" is suggested to be added to FMEA studies for a more robust decision process. This dimension may determine the degree of relevance of failure mode to the application area.

\section{ACKNOWLEDGEMENTS}

The study is conducted in and supported by AN-EL Anahtar ve Elektrikli Ev Aletleri Sanayi A.S.. We thank the Top Management and R\&D Center Team Members for their contributions.

\section{REFERENCES}

1. Hernández, B., Jiménez, J., \& Martín, M. J. (2010). Customer behavior in electronic commerce: The moderating effect of e-purchasing experience. Journal of business research, 63(9-10), 964-971.
2. Gunasekaran, A. (1999). Agile manufacturing: a framework for research and development. International journal of production economics, 62(1-2), 87-105. 
3. Louw, L., \& Droomer, M. (2019). Development of a low cost machine vision based quality control system for a learning factory. Procedia Manufacturing, 31, 264-269.

4. Würschinger, H., Mühlbauer, M., Winter, M., Engelbrecht, M., \& Hanenkamp, N. (2020). Implementation and potentials of a machine vision system in a series production using deep learning and low-cost hardware. Procedia CIRP, 90, 611616.

5. Ardhy, F., \& Hariadi, F. I. (2016, November). Development of SBC based machine-vision system for PCB board assembly automatic optical inspection. In 2016 International Symposium on Electronics and Smart Devices (ISESD) (pp. 386393). IEEE.

6. Gong, Y., Lin, Z., Wang, J., \& Gong, N. (2018). Bringing machine intelligence to welding visual inspection: development of low-cost portable embedded device for welding quality control. Electronic Imaging, 2018(9), 279-1.

7. Korodi, A., Anitei, D., Boitor, A., \& Silea, I. (2020). Image-processing-based low-cost fault detection solution for end-of-line ECUs in automotive manufacturing. Sensors, 20(12), 3520.

8. Adamo, F., Attivissimo, F., Di Nisio, A., \& Savino, M. (2009). A low-cost inspection system for online defects assessment in satin glass. Measurement, 42(9), 1304-1311.

9. Frustaci, F., Perri, S., Cocorullo, G., \& Corsonello, P. (2020). An embedded machine vision system for an in-line quality check of assembly processes. Procedia Manufacturing, 42, 211-218.

10. Parakontan, T., \& Sawangsri, W. (2019, June). Development of the Machine Vision System for Automated Inspection of Printed Circuit Board Assembl. In 2019 3rd International Conference on Robotics and Automation Sciences (ICRAS) (pp. 244-248). IEEE.

11. Di Leo, G., Liguori, C., Pietrosanto, A., \& Sommella, P. (2017). A vision system for the online quality monitoring of industrial manufacturing. Optics and Lasers in Engineering, 89, 162-168.

12. Moru, D. K., \& Borro, D. (2020). A machine vision algorithm for quality control inspection of gears. The International Journal of Advanced Manufacturing Technology, 106(1), 105-123.

13. Safavian, S. R., \& Landgrebe, D. (1991). A survey of decision tree classifier methodology. IEEE transactions on systems, man, and cybernetics, 21(3), 660-674.

14. Song, Y. Y., \& Ying, L. U. (2015). Decision tree methods: applications for classification and prediction. Shanghai archives of psychiatry, 27(2), 130.

15. Wang, C. H., Guo, R. S., Chiang, M. H., \& Wong, J. Y. (2008). Decision tree based control chart pattern recognition. International Journal of Production Research, 46(17), 4889-4901.

16. Matsko, I. I., Logunova, O. S., Pavlov, V. V., \& Matsko, O. S. (2012). Adaptive fuzzy decision tree with dynamic structure for automatic process control system $\mathrm{O}$ of continuous-cast billet production. IOSR Journal of Engineering, 2(8), 5355.

17. Putri, N. K. S., Puika, K. S., Ibrahim, S., \& Darmawan, L. (2018, September). Defect Classification Using Decision Tree. In 2018 International Conference on Information Management and Technology (ICIMTech) (pp. 281-285). IEEE.

18. Chen, J., Lian, Y., \& Li, Y. (2020). Real-time grain impurity sensing for rice combine harvesters using image processing and decision-tree algorithm. Computers and Electronics in Agriculture, 175, 105591.

19. Zhou, Q., Chen, R., Huang, B., Liu, C., Yu, J., \& Yu, X. (2019). An automatic surface defect inspection system for automobiles using machine vision methods. Sensors, 19(3), 644.

20. Lin, Y., Xiang, Y., Lin, Y., \& Yu, J. (2019, September). Defect detection system for optical 
element surface based on machine vision. In 2019 2nd International Conference on Information Systems and Computer Aided Education (ICISCAE) (pp. 415-418). IEEE.

21. Breiman, L., Friedman, J., Stone, C. J., \& Olshen, R. A. (1984). Classification and regression trees. CRC press.

22. Stamatis, D. H. (2003). Failure mode and effect analysis: FMEA from theory to execution. Quality Press.

23. Agarwala, A. S. (1990, January). Shortcomings in mil-std-1629A guidelines for criticality analysis. In Annual Proceedings on Reliability and Maintainability Symposium (pp. 494-496). IEEE.

24. Office of manned space flight, Apollo program, Apollo Reliability and Quality Assurance Office. (1966). Procedure for Failure Mode, Effects and Criticality Analysis (FMECA).

25. Maddalena, S., Darmon, A., \& Diels, R. (2005). Automotive CMOS image sensors. In Advanced Microsystems for Automotive Applications 2005 (pp. 401-412). Springer, Berlin, Heidelberg.

26. Klochkov, Y., Its, A., \& Vasilieva, I. (2016). Development of FMEA method with the purpose of quality assessment of can stock production. In Key Engineering Materials (Vol. 684, pp. 473-476). Trans Tech Publications Ltd.

27. Sharma, K. D., \& Srivastava, S. (2018). Failure mode and effect analysis (FMEA) implementation: a literature review. J. Adv. Res. Aeronaut. Space Sci, 5, 1-17.

28. Spreafico, C., Russo, D., \& Rizzi, C. (2017). A state-of-the-art review of FMEA/FMECA including patents. Computer Science Review, 25, 19-28.

29. Huang, J., You, J. X., Liu, H. C., \& Song, M. S. (2020). Failure mode and effect analysis improvement: A systematic literature review and future research agenda. Reliability Engineering \& System Safety, 106885.
30. Ng, W. C., Teh, S. Y., Low, H. C., \& Teoh, P. C. (2017, September). The integration of FMEA with other problem solving tools: A review of enhancement opportunities. In J Phys Conf Ser (Vol. 890, p. 012139).

31. AIAG-VDA FMEA Handbook 4. Edition (2019)

32. Puvanasvaran, A. P., Jamibollah, N., Norazlin, N., \& Adibah, R. (2014). Poka-Yoke Integration into process FMEA. Australian Journal of Basic and Applied Sciences, 8(7), 66-73.

33. Cohen, J. (1960). A coefficient of agreement for nominal scales. Educational and psychological measurement, 20(1), 37-46.

34. Viera, A. J., \& Garrett, J. M. (2005). Understanding interobserver agreement: the kappa statistic. Fam med, 37(5), 360-363.

35. Chauhan, V., \& Surgenor, B. (2015). A comparative study of machine vision based methods for fault detection in an automated assembly machine. Procedia Manufacturing, 1, 416-428.

36. Kunakornvong, P., \& Sooraksa, P. (2016). Machine vision for defect detection on the air bearing surface. In 2016 International Symposium on Computer, Consumer and Control (IS3C) (pp. 37-40). IEEE.

37. Shen, H., Li, S., Gu, D., \& Chang, H. (2012). Bearing defect inspection based on machine vision. Measurement, 45(4), 719-733.

38. Edinbarough, I., Balderas, R., \& Bose, S. (2005). A vision and robot based on-line inspection monitoring system for electronic manufacturing. Computers in Industry, 56(8-9), 986-996. 